\title{
Behavioural changes caused by diffuse intrinsic pontine glioma
}

\author{
Pedro Tadao Hamamoto Filho' \\ Igor Barreira Magro ${ }^{1}$ \\ Marco Antonio Zanini'
}

1. UNESP - Campus de Botucatu - Department of Neurology, Psychology and Psychiatry - Botucatu - São Paulo - Brasil

KEYWORDS: Glioma. Behaviour. Behavioural symptoms. Brain stem neoplasms.

This five-year-old girl presented with a history of two weeks of behavioural changes (irritability, aggressiveness and school problems). No underlying cause was found on psychiatric assessment. In the following 5 days, she presented a left sixth nerve palsy and ataxic gait and then she was referred to the neurosurgery team. Magnetic resonance imaging showed a diffuse intrinsic pontine glioma DIPG - (Figures A and B). Radiotherapy was then started.

DIPG accounts for $10 \%$ of childhood brain tumours. Most common signs at presentation include corticospinal tract deficits, cranial nerve palsies and ataxia. The brainstem was not regarded as a structure involved in complex affective behaviour, but today it is well established that cerebrocerebellar and cerebellum-cerebral connections play a role in affective and cognitive behavioural. ${ }^{1}$ Actually, behavioural

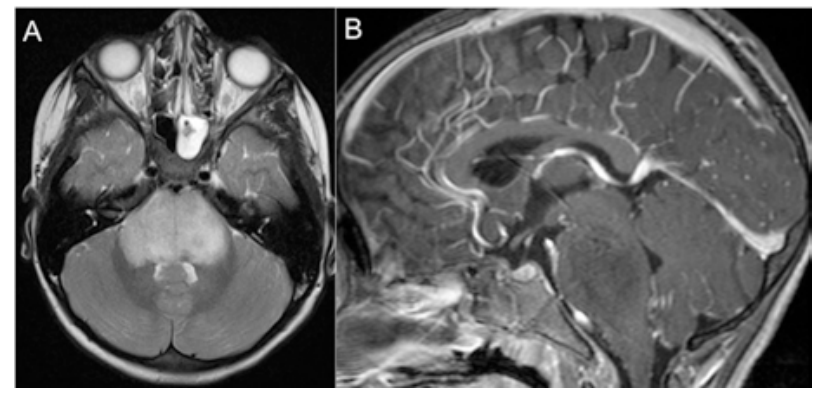

FIGURE. Diffuse intrinsic pontine glioma characterized by a hyperintensity on T2 (A, axial view) and iso-hypointensity on T1 weighted MRI ( $B$, sagittal view). In this case, the lesion did not have significant contrast enhancement.

changes are present in only $5 \%$ of the cases. ${ }^{2,3}$ However, in children with unexplainable behavioural changes, DIPG should be considered as a differential diagnosis. 
PALAVRAS CHAVE: Glioma. Comportamento. Sintomas comportamentais. Neoplasias do tronco encefálico.

\section{REFERENCES}

1. Riva D, Giorgi $C$. The cerebellum contributes to higher functions during development: evidence from a series of children surgically treated for posterior fossa tumours. Brain. 2000;123 (Pt5):1051-61.

2. Wilne S, Collier J, Kennedy C, Koller K, Grundy R, Walker D. Presentation of childhood CNS tumours: a systematic review and meta-analysis. Lancet Oncol. 2007;8(8):685-95.

3. Hargrave DR, Mabbott DJ, Bouffet E. Pathological laughter and behavioural change in childhood pontine glioma. J Neurooncol. 2006;77(3):267-71. 